\title{
Shoot flammability of vascular plants is phylogenetically conserved and related to habitat fire-proneness and growth form
}

\author{
Xinglei Cui ${ }^{1 凶}$, Adrian M. Paterson ${ }^{1}$, Sarah V. Wyse², Md Azharul Alam ${ }^{\circledR}{ }^{1}$, Kévin J. L. Maurin ${ }^{3}$, \\ Robin Pieper1, Josep Padullés Cubino ${ }^{1,4}$, Dean M. O'Connell', Djessie Donkers', Julien Bréda', \\ Hannah L. Buckley5 ${ }^{5}$ George L. W. Perry $\mathbb{1}^{6}$ and Timothy J. Curran ${ }^{1}{ }^{1 凶}$
}

Q1. Terrestrial plants and fire have interacted for at least 420 million years. Whether recurrent fire drives plants to evolve higher flammability and what the evolutionary pattern of plant flammability is remain unclear. Here, we show that phy22 logeny, fire-proneness of habitat and growth form are important predictors of the shoot flammability of 194 indigenous and introduced vascular plant species (Tracheophyta) from New Zealand. The phylogenetic signal of the flammability components and the variation in flammability among phylogenetic groups (families and higher taxonomic level clades) demonstrate that shoot flammability is phylogenetically conserved. Some closely related species, such as in Dracophyllum (Ericaceae), vary in flammability, indicating that flammability exhibits evolutionary flexibility. Species in fire-prone ecosystems tend to be more flammable than species from non-fire-prone ecosystems, suggesting that fire may have an important role in the evolution of plant flammability. Growth form also influenced flammability-forbs were less flammable than grasses, trees and shrubs; by contrast, grasses had higher biomass consumption by fire than other groups. The results show that shoot flammability of plants is largely correlated with phylogenetic relatedness, and high flammability may result in parallel evolution driven by environmental factors, such as fire regime.

Fire has affected the distribution and evolution of terrestrial plants for at least 420 million years $^{1-6}$ and many species have developed adaptations to persist in the face of this disturbance ${ }^{5,7}$. Although a growing number of researchers support the idea that fire has selected some plant species to become more flammable ${ }^{8-12}$ or, in some cases, less flammable ${ }^{11,13}$, others have argued that flammability has not evolved in response to fire, but is the result of exaptations, whereby traits fulfilling other functions also influence flammability ${ }^{14-16}$. Although there is evidence in some taxa that plant flammability has evolved in response to changes in fire regimes $^{10,17,18}$, broad-scale phylogenetic patterns in plant flammability remain unclear. A better understanding of the evolution of flammability would facilitate our understanding of the long-term interactions between fire and plants, and may help to prepare us for a warmer world, in which fire risk may be higher in many regions ${ }^{19}$. One method to decipher the evolutionary patterns of plant flammability is to evaluate variation in flammability with phylogenetic approaches, but few such studies have been reported. These previous studies have mostly focused on specific genera ${ }^{20}$ and used qualitative, rather than quantitative, measures of flammability ${ }^{17,21}$.

We burned shoots (length, $70 \mathrm{~cm}$ ) of 194 species (120 indigenous to New Zealand and 74 exotic species introduced from other parts of the world) from across the Tracheophyta (vascular plants; Supplementary Fig. 1, "Table 1). We measured four components of flammability: ignition frequency (ignitability), burning time (sustainability), maximum temperature (combustibility) and burnt biomass (consumability), and related these to phylogeny, the fire-proneness of the species' habitat and growth form of the species. The selected species showed a wide range of shoot flammability attributes: 22 species did not ignite on our device (ignition frequency of zero), whereas 82 species ignited in $100 \%$ of samples. Mean consumed biomass per species ranged from $0 \%$ to $94 \%$, the mean maximum temperature per species reached $771.5 \pm 23.0^{\circ} \mathrm{C}$ (mean \pm 1 s.e.m.), and mean burning times ranged from $0 \mathrm{~s}$ to 240 s (Supplementary Table 1). Combustibility, consumability and ignitability were strongly positively correlated, whereas sustainability had a weaker correlation with ignitability and consumability (Supplementary Fig. 2).

The integration of flammability data with the phylogeny showed that closely related species tend to have similar flammability (Fig. 1), although flammability varied considerably among some

Table 1 | Results of the phylogenetic tests for flammability components across selected indigenous and introduced New Zealand vascular plants species

Flammability components Pagel's $\lambda$

\begin{tabular}{llr}
\cline { 2 - 3 } & $\lambda$ value & \multicolumn{1}{c}{$\boldsymbol{P}$} \\
\hline Ignition frequency & 0.74 & $<0.001$ \\
Burning time & 0.27 & 0.005 \\
Maximum temperature & 0.51 & $<0.001$ \\
\hline Burnt biomass & 0.48 & $<0.001$ \\
\hline
\end{tabular}

$P$ values give the significance of Pagel's $\lambda(n=190$ species).

'Department of Pest-management and Conservation, Lincoln University, Lincoln, New Zealand. 2Bio-Protection Research Centre, Lincoln University, Lincoln, New Zealand. ${ }^{3}$ School of Science, The University of Waikato, Hamilton, New Zealand. ${ }^{4}$ Department of Ecology, Evolution and Behavior, University of Minnesota, St Paul, MN, USA. ${ }^{5}$ School of Science, Auckland University of Technology, Auckland, New Zealand. ${ }^{6}$ School of Environment, University of

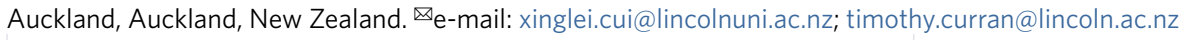




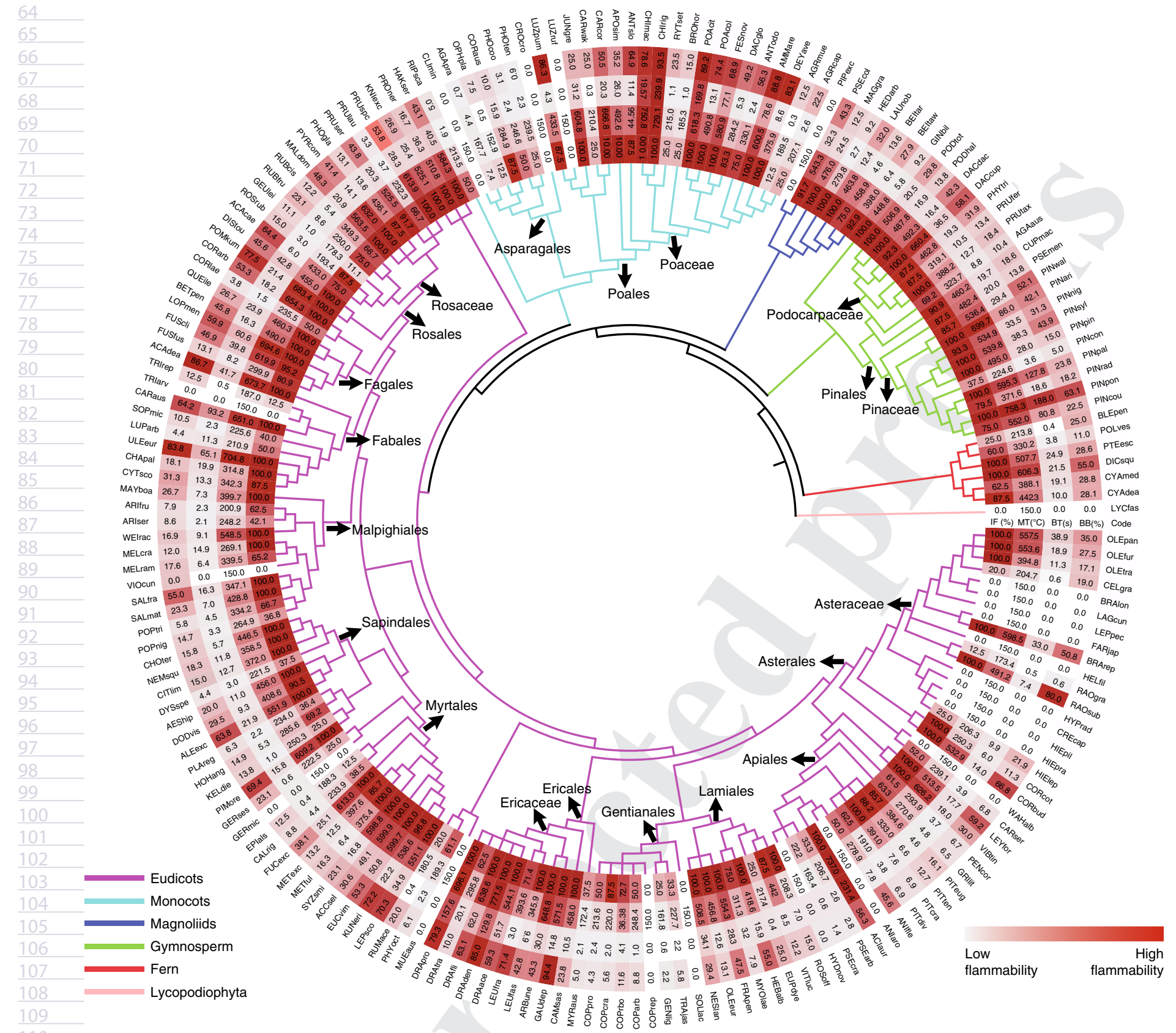

Fig. 1 | Evolution of shoot flammability across the vascular plant phylogeny. The phylogenetic tree ( $n=194$ species) was derived from the Open Tree 29 of Life $^{37}$. Cells from the inside to the outside of the phylogeny are ignition frequency (IF), maximum temperature (MT), burning time (BT) and burnt biomass (BB). The values of the flammability components increase with the intensity of the colour from white to red. The colour of branches indicates different clades. Regular typeface denotes names of families; bold typeface denotes names of higher taxonomic level clades. Species codes are provided in Supplementary Table 1.

closely related species, for example, Dracophyllum (Ericaceae) species. To evaluate the extent to which related species tend to have similar flammability components, we calculated the phylogenetic signal $^{22}$ of each flammability component. We used Pagel's $\lambda$ (ref. ${ }^{22}$; the value varies between 0 (phylogenetic independence) and 1 , where species' traits co-vary in direct proportion to their shared evolutionary history ${ }^{23}$ ) because it is more appropriate than alternatives, such as Blomberg's $K$ (ref. ${ }^{24}$ ), for testing ecologically relevant traits ${ }^{25}$ and situations in which phylogenetic data are incomplete. Pagel's $\lambda$ was statistically significant for all flammability components (Table 1), confirming that flammability is a phylogenetic trait across the broad range of vascular plant taxa that we considered, and demonstrating the usefulness of phylogeny in predicting the flammability characteristics of species of vascular plants. The phylogenetic pattern of flammability was consistent even considering possible biases due to unbalanced data regarding habitat and growth form (Supplementary Information, section 1), although adding more species from different regions of the world may potentially change the phylogenetic signal of flammability. Although it seems probable that species inherited the flammability of their ancestors, the value of the phylogenetic signals (Table 1) indicated that flammability exhibits evolutionary flexibility; for example, there was wide variation in flammability among Poaceae (Poales) and Raoulia (Asteraceae) species (Fig. 1, Supplementary Table 1). The variation 

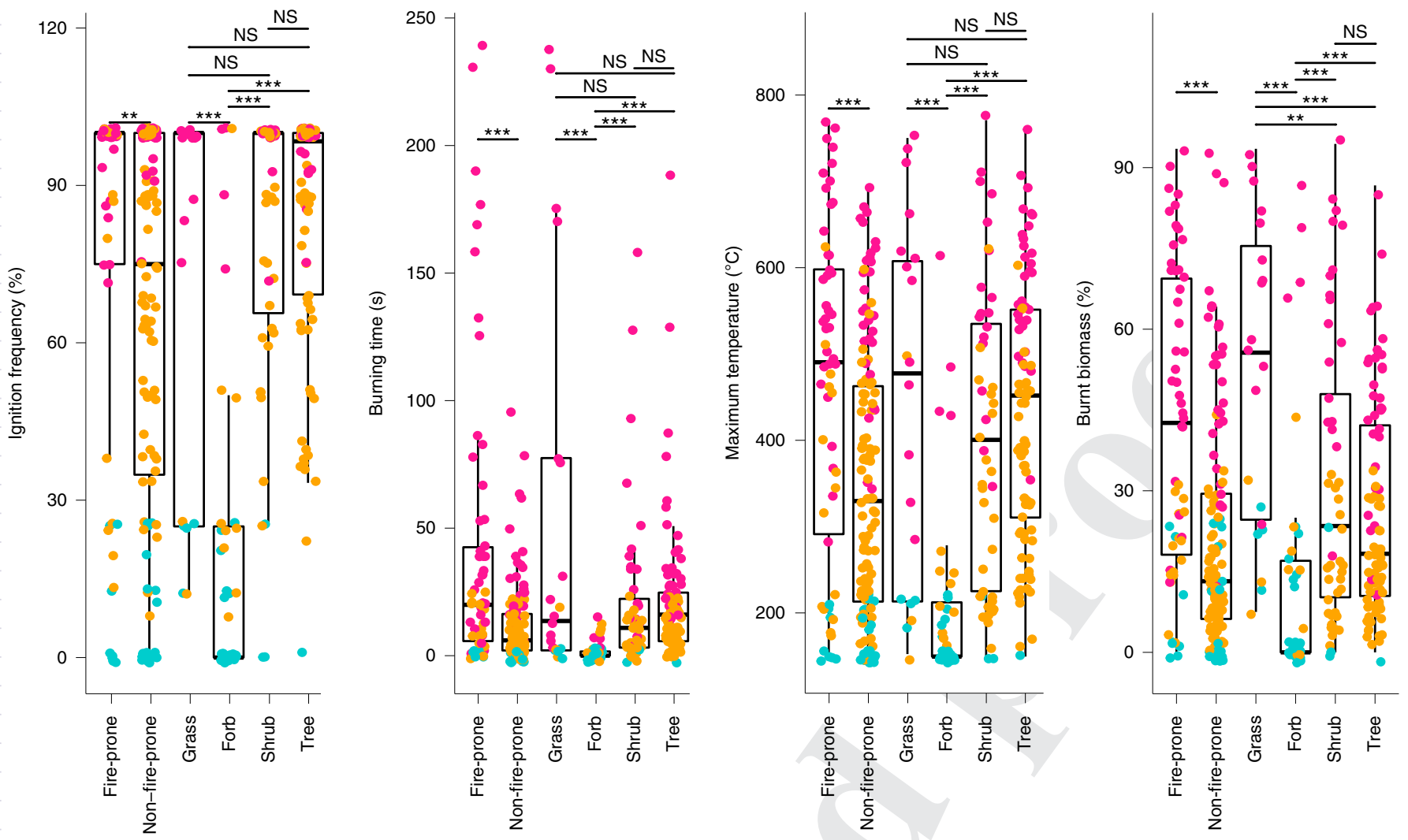

Fig. 2 | Variation in flammability components among plant growth forms ( $n=194$ species) and habitats ( $n=186$ species). The colour of the points 10 indicates the flammability syndrome. Light blue shows low flammability; yellow shows fast flammability; red shows hot flammability. The centre lines show the median values, the box limits indicate the 25 th and 75 th percentiles, and the whiskers indicate the 5th and 95th percentiles. Statistical differences were analysed using one-way analysis of variance. NS, $P>0.05 ;{ }^{\star \star} P \leq 0.01 ;{ }^{\star \star \star} P \leq 0.001$.

among closely related species suggested that factors other than phylogeny may influence flammability. Furthermore, highly flammable species occur in almost any phylogenetic clade across the selected species (Fig. 1, Supplementary Table 1), indicating that high flammability may result in parallel evolution that is driven by environmental factors.

To further explore the variation in flammability among phylogenetic clades, we partitioned the species into different phylogenetic groups at different taxonomic levels (families and higher-taxonomiclevel clades), each with at least five species. Typically, the families Ericaceae, Myrtaceae, Pinaceae and Poaceae had high flammability, whereas Asteraceae had low flammability (Supplementary Fig. 3a). At higher taxonomic levels, Ericales, Pinales, Poales and Myrtales had high flammability, largely reflecting the family-level patterns, whereas Asparagales had low flammability (Supplementary Fig. 3b). Among even broader clades, Pinophyta (conifers) had high flammability, whereas the Lilioid monocots clade generally included low flammability species (Supplementary Fig. 3c). Although only a few phylogenetic clades-with limited replication $(5 \leq n \leq 40)$-were analysed, the flammability variation among phylogenetic clades found here shows that flammability is not randomly distributed across Tracheophyta, but is influenced by phylogeny.

Hypotheses regarding the evolution of flammability were first proposed by Mutch in 1970 ( ref. $^{8}$ ), who suggested that firedependent plant communities burn more readily than non-firedependent communities because natural selection has favoured the development of characteristics that make fire-dependent communities more flammable ${ }^{8}$. Nearly 50 years later, the hypothesis that evolution favours increased flammability in some ecosystems remains controversial ${ }^{9,12,14-16}$. Pausas et al. ${ }^{11}$ suggested that one limitation of research considering the evolution of flammability is the concept of flammability itself. They proposed that species in fire-prone ecosystems can be classified into three flammability strategies: hotflammable (high heat release), fast-flammable (high rate of flame spread) and low-flammability (low ignitability) strategies, and suggested that species in such environments would benefit from acquiring one of these strategies ${ }^{11}$. Several empirical studies have shown that, in fire-prone ecosystems, species can exhibit either low ${ }^{13}$ or high flammability ${ }^{10}$ (for high flammability, either hot or fast flammability), which could be associated with post-fire regeneration strategies of some species, such as post-fire seeders ${ }^{11}$. We classified the 194 species into three groups using model-based clustering on the basis of the four components of flammability that we measured (Supplementary Information, section 2). The group with the lowest value of flammability attributes was identified as low flammability. The group with the highest maximum temperature was considered to be hot flammability. The group with a much shorter burning time than the hot-flammability group was named fast flammability. We also categorized the species as originating from fire-prone or non-fire-prone habitats (see Methods). We found that species from fire-prone habitats tend to have higher flammability than species from non-fire-prone habitats (Fig. 2). We classified 51 out of 59 species in fire-prone ecosystems into fast-flammability and hotflammability syndromes (Supplementary Table 1), indicating that the prevalent flammability syndrome of species in these ecosystems involves being either fast or hot flammable. Few species (30 out of 127) from non-fire-prone habitats were classified into hot-flammability (Supplementary Table 1), suggesting that high heat release has few evolutionary advantages in such environments. These results reaffirm the value of the low-fast-hot-flammable framework in the 
consideration of plant flammability from an evolutionary perspective. However, it should be noted that, in our study, there were some species in each flammability syndrome that had flammability traits that were more similar to species in a different flammability syndrome than their own (Supplementary Fig. 5). Thus, flammability should be treated as a continuous trait, and the flammability syndrome should be treated as a spectrum, rather than a collection of discrete groups.

Another potential influence on flammability is growth form (physiognomy). It is widely acknowledged that flammability varies among species ${ }^{26}$, but variation in flammability across growth forms is less widely reported ${ }^{27}$. Here we classified all 194 species into four possible growth forms-trees, shrubs, grass or forbs-on the basis of the descriptions from the New Zealand Plant Conservation Network (http://www.nzpcn.org.nz). Although flammability varied within growth forms, it also varied significantly among growth forms (Fig. 2). Forbs were consistently the least flammable growth form, having significantly lower values for all flammability components. Grasses had significantly higher consumability (burnt biomass) than other growth forms, but otherwise generally showed similar levels of flammability to trees and shrubs. The evolution of growth forms since the early diversification of terrestrial plants has a complex history of innovation, complexification, simplification, conservatism, radiation and extinction ${ }^{28}$. Plant growth form is largely determined genetically, but it can be modified by environmental and biotic factors ${ }^{28}$, therefore influencing flammability.

We assessed the shoot flammability of 194 vascular plants and explored evolutionary patterns of flammability using a phylogenetic approach. Our analyses showed that there is a significant phylogenetic signal of shoot flammability across selected vascular plants (Table 1), indicating that closely related taxa tend to have similar flammability and that the shoot flammability of indigenous and introduced New Zealand vascular plants was phylogenetically conserved. The fact that flammability has a phylogenetic component is consistent with the idea that flammability is an emergent trait that can be selected for. However, we cannot rule out that flammability comprises some exaptations, as the physical and biological conditions in which species live were not considered in this research. The significant variation in flammability among habitats with differing prevalence of fire-proneness suggests that fire regimes had an important role in the evolution of flammability traits and inferred that species from fire-prone plant communities are likely to burn more readily than those from non-fire-prone communities. Finally, growth form also influenced flammability. The fact that phylogeny, fire proneness of habitat and growth form all influence the flammability of a wide range of indigenous and introduced New Zealand species of vascular plants suggests that relative shoot flammability can be predicted from taxonomic relatedness, habitat fire regime and growth form. The results may enable fire managers and ecologists to estimate flammability for a wide range of species of vascular plants on the basis of these characteristics, therefore expanding our knowledge of how well plants burn at the species level. However, given the wide variability in flammability within each of these predictors, fire managers still need to observe the behaviour and outcomes of fires in specific contexts.

\section{Methods}

Sample collection and measurement of shoot flammability. Samples of 194 plant species (120 indigenous to New Zealand and 74 exotic species introduced from other parts of the world) were collected across a broad range of habitats in New Zealand. Nomenclature of species was standardized across the dataset and updated where necessary by querying species names against the New Zealand Plant Conservation Network (http://www.nzpcn.org.nz).

For most species, samples were 70-cm-long, sun-exposed terminal branches from healthy, reproductively mature plants. For small plants (such as low grasses and forbs), whole plants were collected to preserve the plant's architecture (the roots were removed before burning). Where grasses and forbs were taller than
$70 \mathrm{~cm}$, the lower $70 \mathrm{~cm}$ was sampled and material above that length trimmed and removed. For lianas, a $70 \mathrm{~cm}$ shoot was cut from a mature, leafy terminal branch. For ferns, a section or a whole single frond of up to $70 \mathrm{~cm}$ was collected. Shoot samples were collected from each of at least six separate healthy individual plants and kept in separate sealed plastic bags to preserve the plant's architecture. The samples were kept in cool locations during collection and then stored at $4-8^{\circ} \mathrm{C}$ as soon as possible. Further details on collection protocols are provided by Wyse et al. ${ }^{26}$ and Padullés et al. ${ }^{29}$.

Measurement of shoot flammability was performed according to the methods of Wyse et al. ${ }^{26}$ and Jaureguiberry et al. ${ }^{30}$. Our device (Supplementary Fig. 1) was built according to the specifications of Jaureguiberry et al. ${ }^{30}$ and adjusted to meet New Zealand safety standards. Before burning, all of the shoot samples were airdried at room temperature for $24 \mathrm{~h}$ to match the sample moisture content to the ignition source (according to Wyse et al. ${ }^{26,31}$ ). Plants samples were then preheated at $\sim 150^{\circ} \mathrm{C}$ for $2 \mathrm{~min}$ by the burners in the device. After preheating, the blowtorch was turned on for $10 \mathrm{~s}$ to ignite the samples. Here, ignition frequency (that is, the percentage of samples that sustained fire after the blowtorch was turned off) was recorded to represent ignitibility. Maximum temperature of the burning sample was recorded to represent combustibility, using an infrared laser thermometer (Fluke 572, Fluke) after the blowtorch was turned off. Samples that failed to be ignited were given a value of $150^{\circ} \mathrm{C}$ as the temperature of the grill of the device. Sustainability was measured as the duration that the sample burned after turning off the blowtorch. Finally, consumability was recorded as the percentage of burnt biomass after the flame extinguished, calculated by visual observation performed by at least two observers. Samples that did not burn without the blowtorch were assigned zeros for sustainability and consumability.

Data collection. The fire-proneness of the habitats of species were assigned depending on the description of habitat type of the biogeographical origin of each species from numerous sources (Supplementary Table 1). Species were designated as coming from a fire-prone habitat if they are found in ecosystems that are likely to have recurrent fires, such as grasslands, savanna, shrublands or certain forest types, such as eucalypt forests in Australia and pine forests in the northern hemisphere. Species that are found predominantly in rainforest or closed forest, where fire is unlikely to be a recurrent disturbance and/or a selective pressure, were considered as originating from non-fire-prone habitats. Cultivated varieties (cultivars) of plants that now occur primarily in gardens were allocated a fire-prone status based on the habitat of the parent species, as we assumed that the fireprone status of the habitat of cultivated species is the same as that of their parental species. Species in the Pinaceae were all classified from fire-prone habitat ${ }^{21}$ Although this is a simplification of global fire regimes, there are no clear alternative means of categorizing fire regimes of native habitats for such a large number of species.

All of the species were also classified into four growth forms: trees, shrubs, grass or forbs on the basis of the descriptions from the New Zealand Plant Conservation Network (http://www.nzpcn.org.nz). Ferns were classified as shrubs or trees depending on the description. All of the vines were classified as shrubs.

Testing for phylogenetic signal. To evaluate the phylogenetic signal of flammability components, a dated phylogeny with 190 species was obtained from a previously published phylogeny ${ }^{32}$ using Phylomatic ${ }^{32,33}$. Branch lengths were estimated using the BLADJ algorithm on the basis of fossil calibrations of vascular plants $\mathrm{s}^{34,35}$. The multi2di function was used to resolve the polytomies within the phylogeny ${ }^{36}$. Another phylogeny without branch lengths for all of the 194 species was constructed with the Open Tree of Life using the R package rotl 3.0.10 (refs. ${ }^{37,38}$ ). The second phylogeny was used to visualize the flammability patterns across the phylogeny (Fig. 1).

We evaluated the phylogenetic signal using the R package Phytools 0.6-99 $\left(\right.$ ref. $\left.{ }^{39}\right)$. This index uses Brownian models and includes branch-length distances to test for phylogenetic signals against random patterns.

Statistical analysis. All statistical analyses were performed using R 3.5.0 (ref. ${ }^{40}$ ). Principal coordinates analysis was performed using the $\mathrm{R}$ packages vegan 2.5-6 (ref. ${ }^{41}$ ) and labdsv 2.0-1 (ref. ${ }^{42}$ ). The relationship among the flammability components was analysed using the R package PerformanceAnalytics 1.5 .3 (ref. ${ }^{43}$ ). Flammability syndromes were classified with the four flammability components using model-based clustering ${ }^{44}$. Model-based clustering was performed using the $\mathrm{R}$ package mclust 5.4 .5 (ref. ${ }^{45}$ ). One-way analysis of variance was used to analyse the variation of flammability among growth forms, habitats and phylogenetic groups.

Reporting Summary. Further information on research design is available in the Nature Research Reporting Summary linked to this article.

\section{Data availability}

The source data for Fig. 1 are available with the paper.

Received: 27 September 2019; Accepted: 11 March 2020; 


\section{References}

1. Scott, A. C. Burning planet: The Story of Fire Through Time. (Oxford Univ. Press, 2018).

2. Bond, W. J., Woodward, F. I. \& Midgley, G. F. The global distribution of ecosystems in a world without fire. N. Phytol. 165, 525-538 (2005).

3. Bond, W. J. \& Keeley, J. E. Fire as a global 'herbivore': the ecology and evolution of flammable ecosystems. Trends Ecol. Evol. 20, 387-394 (2005).

4. Bowman, D. M. et al. Fire in the Earth system. Science 324, 481-484 (2009)

5. He, T. \& Lamont, B. B. Baptism by fire: the pivotal role of ancient conflagrations in evolution of the Earth's flora. Natl Sci. Rev. 5, 237-254 (2017).

6. He, T., Lamont, B. B. \& Pausas, J. G. Fire as a key driver of Earth's biodiversity. Biol. Rev. 94, 1983-2010 (2019).

7. Keeley, J. E., Pausas, J. G., Rundel, P. W., Bond, W. J. \& Bradstock, R. A. Fire as an evolutionary pressure shaping plant traits. Trends Plant Sci. 16, 406-411 (2011).

8. Mutch, R. W. Wildland fires and ecosystems-A hypothesis. Ecology 51, 1046-1051 (1970).

9. Bond, W. J. \& Midgley, J. J. Kill thy neighbour: an individualistic argument for the evolution of flammability. Oikos 73, 79-85 (1995).

10. Pausas, J. G., Alessio, G. A., Moreira, B. \& Corcobado, G. Fires enhance flammability in Ulex parviflorus. N. Phytol. 193, 18-23 (2012).

11. Pausas, J. G., Keeley, J. E. \& Schwilk, D. W. Flammability as an ecological and evolutionary driver. J. Ecol. 105, 289-297 (2017).

12. Archibald, S. et al. Biological and geophysical feedbacks with fire in the Earth system. Environ. Res. Lett. 13, 033003 (2018).

13. Simon, M. F. et al. Recent assembly of the Cerrado, a neotropical plant diversity hotspot, by in situ evolution of adaptations to fire. Proc. Natl Acad. Sci. USA 106, 20359-20364 (2009).

14. Midgley, J. J. Flammability is not selected for, it emerges. Aust. J. Bot. 61, 102-106 (2013).

15. Bowman, D. M. J. S., French, B. J. \& Prior, L. D. Have plants evolved to self-immolate? Front. Plant Sci. 5, 590 (2014)

16. Snyder, J. R. The role of fire: much ado about nothing? Oikos 43, 404-405 (1984).

17. He, T., Lamont, B. B. \& Downes, K. S. Banksia born to burn. N. Phytol. 191, 184-196 (2011).

18. Moreira, B., Castellanos, M. C. \& Pausas, J. G. Genetic component of flammability variation in a Mediterranean shrub. Mol. Ecol. 23, 1213-1223 (2014).

19. Doerr, S. H. \& Santín, C. Global trends in wildfire and its impacts: perceptions versus realities in a changing world. Proc. R. Soc. B 371, 20150345 (2016)

20. Engber, E. A. \& Varner, J. M. III Patterns of flammability of the California oaks: the role of leaf traits. Can. J. Forest Res. 42, 1965-1975 (2012).

21. He, T., Pausas, J. G., Belcher, C. M., Schwilk, D. W. \& Lamont, B. B. Fire-adapted traits of Pinus arose in the fiery Cretaceous. N. Phytol. 194, 751-759 (2012).

22. Pagel, M. Inferring the historical patterns of biological evolution. Nature 401, 877-884 (1999).

23. Freckleton, R. P., Harvey, P. H. \& Pagel, M. Phylogenetic analysis and comparative data: a test and review of evidence. Am. Naturalist 160, 712-726 (2002).

24. Blomberg, S. P., Garland, T. Jr \& Ives, A. R. Testing for phylogenetic signal in comparative data: behavioral traits are more labile. Evolution 57, 717-745 (2003).

25. Molina-Venegas, R. \& Rodríguez, M. Á. Revisiting phylogenetic signal; strong or negligible impacts of polytomies and branch length information? BMC Evol. Biol. 17, 53 (2017).

26. Wyse, S. V. et al. A quantitative assessment of shoot flammability for 60 tree and shrub species supports rankings based on expert opinion. Int. J. Wildland Fire 25, 466-477 (2016).

27. Santacruz-García, A. C., Bravo, S., del Corro, F. \& Ojeda, F. A comparative assessment of plant flammability through a functional approach: the case of woody species from Argentine Chaco region. Austral Ecol. 44, 1416-1429 (2019).

28. Rowe, N. \& Speck, T. Plant growth forms: an ecological and evolutionary perspective. N. Phytol. 166, 61-72 (2005)
29. Padullés Cubino, J., Buckley, H. L., Day, N. J., Pieper, R. \& Curran, T. J. Community-level flammability declines ovęr 25 years of plant invasion in grasslands. J. Ecol. 106, 1582-1594 (2018).

30. Jaureguiberry, P., Bertone, G. \& Díaz, S. Device for the standard measurement of shoot flammability in the field. Austral Ecol. 36, 821-829 (2011).

31. Wyse, S. V., Perry, G. L. W. \& Curran, T. J. Shoot-level flammability of species mixtures is driven by the most flammable species: implications for vegetationfire feedbacks favouring invasive species. Ecosystems 21, 886-900 (2017).

32. Slik, J. F. et al. Phylogenetic classification of the world's tropical forests. Proc. Natl Acad. Sci. USA 115, 1837-1842 (2018).

33. Webb, C. O. \& Donoghue, M. J. Phylomatic: tree assembly for applied phylogenetics. Mol. Ecol. Resour. 5, 181-183 (2005).

34. Webb, C. O., Ackerly, D. D. \& Kembel, S. W. Phylocom: software for the analysis of phylogenetic community structure and trait evolution. Bioinformatics 24, 2098-100 (2008).

35. Gastauer, M. \& Meira-Neto, J. An enhanced calibration of a recently released megatree for the analysis of phylogenetic diversity. Braz. J. Biol. 76, 619-628 (2016)

36. Paradis, E., Claude, J. \& Strimmer, K. APE: analyses of phylogenetics and evolution in R language. Bioinformatics 20, 289-290 (2004).

37. Hinchliff, C. E. et al. Synthesis of phylogeny and taxonomy into a comprehensive tree of life. Proc. Natl Acad. Sci. USA 112, 12764-12769 (2015).

38. Michonneau, F., Brown, J. W. \& Winter, D. J. rotl: an R package to interact with the Open Tree of Life data. Methods Ecol. Evol. 7, 1476-1481 (2016).

39. Revell, L. J. phytools: an R package for phylogenetic comparative biology (and other things). Methods Ecol. Evol. 3, 217-223 (2012).

40. R Core Team R: A Language and Environment for Statistical Computing (R Foundation for Statistical Computing, 2017)

41. Oksanen, J. et al. vegan: community ecology package. $\mathrm{R}$ package version 2 (2014)

42. Roberts, D. W. \& Roberts, M. D. W. labdsv: ordination and multivariate. (2016).

43. Peterson, B. G. et al. PerformanceAnalytics. (R Team Cooperation, 2018).

44. Banfield, J. D. \& Raftery, A. E. Model-based Gaussian and non-Gaussian clustering. Biometrics, 803-821 (1993)

45. Fraley, C., Raftery, A. \& Scrucca, L. mclust: normal mixture modeling for model-based clustering, classification, and density estimation. R package version 4 (2014)

\section{Acknowledgements}

We thank B. Murray and D. Schwilk for their comments on a draft of this manuscript. X.C. was funded by Lincoln University, New Zealand.

\section{Author contributions}

The original idea was conceived by T.J.C., S.V.W. and G.L.W.P. This project was developed and designed by X.C., T.J.C., A.M.P., S.V.W., G.L.W.P. and H.L.B. Flammability data were collected by T.J.C., S.V.W., M.A.A., J.P.C., X.C., K.J.L.M., R.P., J.B., D.D. and D.M.O. X.C. performed the statistical analyses with advice from A.M.P., T.J.C., S.V.W., M.A.A., K.J.L.M. and G.L.W.P. X.C. and T.J.C. led the writing of the manuscript, with input from all of the co-authors. All of the authors read and approved the final manuscript.

\section{Competing interests}

The authors declare no competing interests.

\section{Additional information}

Supplementary information is available for this paper at https://doi.org/10.1038/ s41477-020-0635-1.

Correspondence and requests for materials should be addressed to X.C. or T.J.C

Peer review information Nature Plants thanks Sandra Bravo, Pedro Jaureguiberry and James Kirkpatrick for their contribution to the peer review of this work.

Reprints and permissions information is available at www.nature.com/reprints.

Publisher's note Springer Nature remains neutral with regard to jurisdictional claims in published maps and institutional affiliations.

(C) The Author(s), under exclusive licence to Springer Nature Limited 2020 